\title{
Forensic engineering - fib MC 2020 and existing structures
}

\author{
Stuart Matthews ${ }^{1, \mathrm{~A}}$ and Giuseppe Mancini ${ }^{2}$ \\ ${ }^{1}$ Building Research Establishment Ltd., Watford, WD25 9XX, UK \& Convenor $f i b$ T10.1 \\ ${ }^{2}$ Department of Structural \& Geotechnical Engineering, Corso Duca degli Abruzzi 24, Torino, Italy \& Co-convenor fib T10.1
}

\begin{abstract}
The $f i b$ (Fédération Internationale du Béton) is developing a new fib Model Code for Concrete Structures, under a working title of Model Code 2020 (MC2020). Numerous aspirational goals have been identified for MC2020. It will be a single code dealing with both new and existing concrete structures, which is both the design of new structures and all the activities relating to the assessment, interventions and the through-life management and care of existing concrete structures, including matters relating to durability and service life design. MC2020 will incorporate many improvements and extensions to the guidance available in the current $f i b$ Model Code for Concrete Structures - fib Model Code 2010 (MC2010). The new and extended models, in association with the other aspects of the updated guidance, will provide improved technical capabilities for undertaking forensic engineering studies of existing concrete structures. These concepts are illustrated by a number of case studies of existing concrete structures subject to damage / deterioration / other inadequacies, as well as associated intervention works. Improved technical guidance provisions will allow forensic engineers to gain a better understanding of the behaviour of existing concrete structures, enabling better judgements to be made of how they behave in-service \& what measures / interventions are most appropriate to extend their useful life.
\end{abstract}

\section{Introduction to $\mathrm{fib} \mathrm{MC2020}$ project}

A new fib Model Code for Concrete Structures, with a working title of Model Code 2020 (MC2020), is being prepared. In June 2016 the fib Technical Council approved the start of activities on the MC2020 project under the auspices of COM10: Model Codes, which in turn initiated Task Group 10.1: Model Code 2020 in October 2016 to undertake the preparation of a single general code fully integrating the provisions for the design of new concrete structures with matters relating to the through-life management and care of existing concrete structures.

Accordingly, MC2020 will need to deal with both the design of new structures and all the activities associated with the through-life management and care of existing concrete structures, including matters such as in-service assessment and interventions to extend the life / improve the performance of these structures.

To that end, MC2020 will take sustainability as a fundamental requirement, based upon a holistic treatment of societal needs and impacts, life-cycle cost and environmental impacts aligned with the United Nations Sustainable Development Goals [1].

MC2020 is an ambitious project building on the achievements of fib MC2010 [2] and its treatment of the conservation of existing concrete structures. The vision for MC2020 is that the detail of its coverage of these matters will go beyond the point reached by fib MC2010, recent ISO codes, such as ISO 16311 [3-6], and the activities to extend the application of the Eurocodes [eg. 7-9] to existing concrete structures. A number of $f i b$ technical workshops and discussions were held, involving participants from around the world, which helped to define and clarify the goals for MC2020.

Amongst other matters, these have developed ideas on how to extend fib MC2010 and its treatment of durability design of new structures and of the assessment and conservation of existing concrete structures. The breadth and extent of relevant material to be addressed in MC2020 is considerable and creates a significant challenge for those preparing the new structural design and assessment code.

MC2020 provides an important opportunity to further advance current approaches to the sustainable design, construction and through-life care of concrete structures. Central to this will be how we formulate and verify performance requirements for concrete structures within a holistic sustainability framework utilising the widelyaccepted 'three pillars of sustainability' of social, environmental and economic performance. Such an approach provides a way to recognise the great benefits concrete structures provide to humankind's global society, along with their impacts on that society and the wider environment, as well as their economic cost and return.

Adopting this integrated life-cycle approach, the requirements for social performance will have defining implications for subsidiary performance requirements critical to structural design and assessment procedures. These are matters such as human and environmental safety, structural reliability, design service life, durability, serviceability and other social aspects, such as aesthetics, adaptability, maintenance, etc.

Based upon the wider social context, there may be requirements for specific performances such as the robustness of the structure, the resilience of its functionality, etc. There is ongoing debate about how

\footnotetext{
A Corresponding author: matthewss@bre.co.uk
} 
these aspects, along with the verification of the associated performance requirements, might be best dealt with in the organisation of MC2020. While the approach adopted has to be philosophically robust, its implementation needs a practical and convenient methodology for its use.

There are many different (and competing) factors which could form parts of the overall future of the design, construction and through-life care of concrete structures, and therefore are potentially topics which might be addressed by MC2020.

New concrete materials and technologies will be critical components to reducing the environmental impacts of concrete construction. The simple substitution of additions, such as fly ash and blast-furnace slag powders for cement, will not be enough. New binders, together with new admixtures and processing technologies, will be needed. With their different chemistry, these pose new challenges but also offer new opportunities. Important considerations include their long-term performance and durability of concretes made with them in demanding service environments.

The above issues also link to durability and service life design [11], areas where the MC2020 project seeks to encourage developments which will lead to advances including improvements in matters such as material characterisation, deterioration modelling and environmental / performance monitoring.

Discussions about the potential nature and coverage of MC2020 have highlighted the rapid pace of technical development in a many areas including those relating to materials, design, numerical analysis, structural assessment, monitoring, construction and interventions, to mention just a few. It is anticipated that the pace at which such technological developments occur will continue to increase. MC2020 needs to be future looking so that it is able to accommodate and not hinder future technological progress, thereby facilitating the ongoing evolution of concrete and reinforcing materials, associated technologies and the structural forms which might potentially be created using them.

However, the implications of the potential developments in intervention materials and associated technologies for protection, repair, rehabilitation and enhancement of the current condition and performance of existing concrete structures should not be forgotten. These are fertile areas of technological advance.

The inclusion in MC2020 of activities associated with the through-life management and care of existing concrete structures also poses substantial challenges, especially when the potential ramifications of damage and material deterioration are considered. Inclusion of these aspects will require some restructuring of the current fib Model Code document as it will be necessary to introduce significantly more information about the processes and procedures involved. In order to keep MC2020 to a manageable size, it is proposed that valuable background technical material be contained in a suite of supporting $f i b$ Bulletins, with these publications preferably being developed and made available as work on MC2020 progresses. Ideally these background documents will disseminate of up-to-date results and the evolution of MC2020 concepts and thinking, and will also allow for timely feedback in the final stage of harmonisation of MC2020. The same principle will be applied to all topics addressed in MC2020.

A series of $f i b$ technical workshops and discussions, involving participants from around the world, have helped to define and clarify the goals for MC2020. So far these events have been held in The Hague, Madrid, Lausanne, Delft and Barcelona.

At the time of writing there have also been MC2020 international promotional and consultative events in Brussels, Rotterdam, Tokyo, Cape Town, Adelaide, Sao Paulo and Denver. Other events are planned. The above events produced wide ranging discussions which touched upon many topics including those noted below:

- General concepts for sustainability and future model code advancement

- Fundamental principles and reliability concepts for new and existing structures

- Models and material characterisation for existing structures

- Inspection, maintenance and retrofitting of existing structures, and

- Evaluation of, decision-making about and management and care of existing structures.

In terms of specific points to be addressed in MC2020, many of these relate to the following:

- Revision and / or extension of basic principles and concepts

- Revision and / or development of principles of structural design and assessment

- Extension of the provisions on materials and their modelling

- Extension of the provisions on interface characteristics between different materials

- Revision of the provisions for design and the development of provisions for assessment

- Extension of the provisions relating to construction and interventions

- Updating the provisions relating to conservation and through-life management \& care, and

- Updating / extending the provisions on recycling, dismantlement and end of life aspects

It is envisaged that MC2020 will provide a through-life management approach for new and existing structures which includes consideration of matters such as:

- Sustainability objectives that balance social, environment and cost perspectives;

- Promotion of structural safety, serviceability and durability;

- Use of advanced life-cycle cost methods,

- Reliability concepts, that take account of uncertainties and risk;

- Use of performance-based concepts to remove inappropriate constraints on the use of novel types materials and approaches;

- Use of improved models for assessment of initiation and propagation phases of deterioration that consider the structural, risk and reliability implications;

- Provision of generalised models allowing for implementation of the level of approximation approach (see later); 
- Attention to new types of concrete and new techniques for construction and interventions,

- Definition of test methods, and performance evaluation of concrete;

- Worldwide knowledge of materials and structural behaviour, and recognises the differing needs of engineering communities around the world;

- Recognition of the importance of robustness and redundancy in the behaviour of structures;

- Paying particular attention to the effect of material degradation;

- Guidance on dealing with structural arrangements which are not recognised in contemporary codes;

- Treatment of the end-of-service-life issues such as demolition and disposal including safety and structural aspects, and

- Guidelines to practitioners when provisions in other standards are deficient or lacking.

It is envisaged that all $f i b$ Commissions, along with members of the wider $f i b$ family, will contribute to the drafting of MC2020. It is also desirable that input should be received from all geographic regions (Africa, Asia, Australasia, Europe, North and South America) to bring insights that would not otherwise be gained.

Additionally, it is proposed that liaison / cooperation be sought with other international organisations working on relevant topics, including bodies such as CEN, CIA, ISO, JCI, PCI, JCSS and RILEM.

Cooperation with international organisations is being sought via various mechanisms including the holding of joint events, such as the joint $f i b$, JCSS and RILEM Durability Workshop held in November 2017 in Delft, the Netherlands. Such events provide an important focus and stimulus for participation in the work on technical topics and give a basis for the exploration of the range of technical practice employed in various regions of the world and by different professional groups.

Another component of the activities to take the Model Code work forward are the MC2020 Action Groups which have been established to focus on specific technical topics. Currently the following twelve Action Groups are in existence / are envisaged:

AG1 Action Group: Databases

AG2 Action Group: Shear and punching

AG3 Action Group: Bond

AG4 Action Group: Durability \& service life design

AG5 Action Group: Detailing

AG6 Action Group: Fire

AG7 Action Group: Seismic design \& assessment

AG8 Action Group: Non-linear finite element modelling (AG: NLFEM)

AG9 Action Group: Structural health monitoring and testing (AG: SHM and testing)

AG10 Action Group: Robustness

AG11 Action Group: Fatigue

AG12 Action Group: Impact and explosion

The vision for the MC2020 Action Groups is that they will draw together knowledge and expertise in their respective technical topic areas, both within and outside $f i b$, as is appropriate in order to bring forward relevant contributions to MC2020.
Finally, consideration will need to be given to new ways of delivering MC2020, with digital delivery being foreseen alongside the traditional hardbound book format. A digital delivery format will facilitate the periodic maintenance of MC2020 by a standing committee, as well as its subsequent evolution.

\section{Contemporary, recent, old and innovative / new materials}

Adequate knowledge about the properties of the materials used in an existing structure is an important aspect of the assessment process, potentially allowing conclusions to be drawn about the adequacy of these materials relative to the structural and other performance requirements. Such information permits decisions to be made about the through-life management of the existing structure, along with the need for any interventions that are required to extend its useful life or upgrade its performance.

Of course the structures that we build today become tomorrow's existing structures, so those that are formed using today's innovative / new materials will become part of the diverse population of existing structures built with an ever wider range of natural, manufactured, waste and re-cycled materials. In the future this mix of materials will become even more diverse as concretes are made with what we consider to be new binders, especially as these come into general use.

As the number of concrete types increases and their hardened properties develop beyond those which are currently available, this will add to the complexity and diversity of the materials in use - which will, in turn, require a greater understanding of materials employed.

Up to now concrete properties (such as shrinkage, creep, elastic modulus, those related to durability, etc) have generally been expressed as a function of the concrete compressive strength, determined using standard tests. However, with recent and ongoing developments in concrete technology, it has been recognised for some time that it is necessary to break this linkage and thereby uncouple the different performance characteristics of a concrete from its specified compressive strength. It is anticipated that use of microstructure models for concrete, linking durability to porosity and transport coefficients, will become an increasingly useful and commonly used design tools. Accordingly MC2020 is expected to include appropriate constitutive relationships for the different concrete properties. These aspects have particularly come to the fore with the development of the concept of 'defined performance' concretes.

The determination of the properties of the structural materials employed will require the use of suitable measurement methods and non-destructive testing / sensing techniques, employed both at the site and in the laboratory, as appropriate.

New understandings have come from recent developments in cementitious materials and associated programmes of material testing, in some cases finding unexpected changes in behaviours which are at odds with those previously observed and anticipated. The shrinkage and creep properties of high and ultra-high performance 
concretes are examples of such findings - the measured values are considerably greater than those predicted on the basis of past experience with lower grade concretes [12].

Attention also has to be given to the properties of older types of materials, such as plain reinforcing bars, which are not included in the scope of modern structural design codes, but which commonly have to be considered in relation to the assessment of existing concrete structures dating from earlier eras of construction.

Also account may need to be taken of the properties of old concrete which could have been influenced by the stress levels experienced by the concrete whilst in-service. For example, Figure 1 illustrates how chloride diffusion into concrete can be affected by the stress level experienced by the concrete.

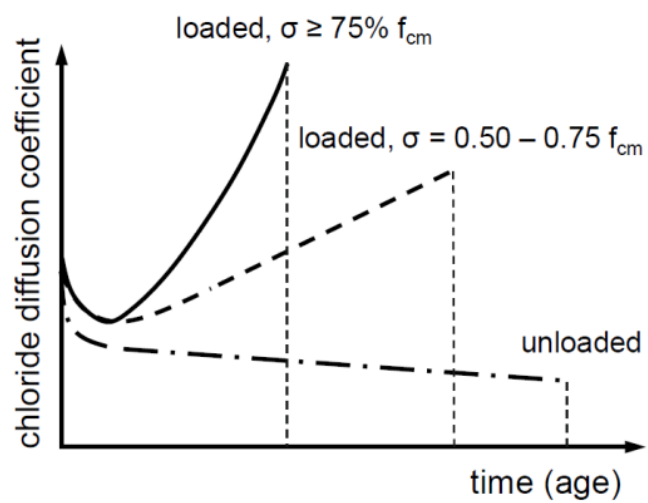

Fig. 1. Effect of structural loading stress on chloride diffusion coefficient (HS Müller, TG10.1 meeting, Barcelona 2017)

This finding also suggests that laboratory measured chloride diffusion coefficient values for use in design may need to be adjusted to take account of the actual stress situation which will be experienced in-service. This could become an increasingly significant matter in the future as the use of more highly stressed higher-strength concretes (ie. UHPC / UHPFRC) increases.

The compressive strength and the carbonation resistance of old concretes are also influenced to varying degrees by the stress levels experienced by the concrete whilst in-service, as is illustrated by Figures 2 and 3. It is apparent that the effects of ageing are not adequately described by ongoing hydration and that interactions between the loading and the environment also play an important role, which introduces further factors which need to be better understood and potentially taken into account in assessments made upon existing concrete structures.

Figure 4 illustrates the well-known relationship of how the carbonation of concrete influences the chloride binding capacity of concrete, with carbonation potentially releasing bound chlorides to promote the corrosion of embedded steel reinforcement. This is another factor that may need to be taken into account in an assessment being made upon existing concrete structures.

It is also important to recognise that current durability models for the ingress of carbonation and chloride ions into concrete are based on limited data. For example, the ageing factor developed from European structures in a limited number of exposure situations is used worldwide for exposures which are not always the same as the structures, or the materials, from which they were determined. Potentially this could have a significant influence upon the expected durability performance and the difference between the predicted performance and that actually achieved. Measuring the ageing factors for materials and exposures directly relevant to the structure to be built will increase the certainty of the analysis predicting potential in-service performance.

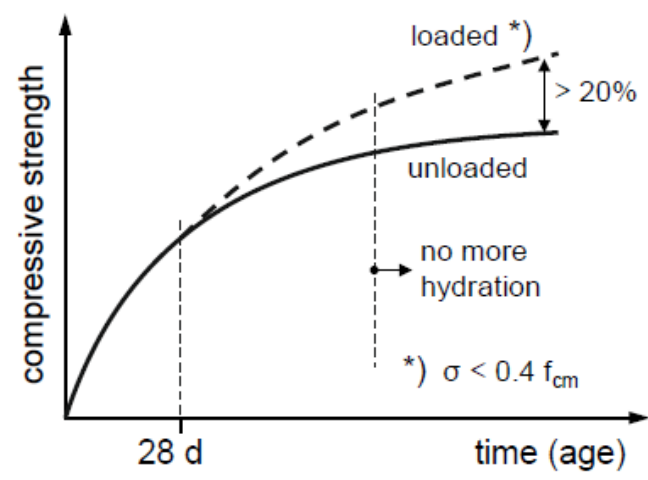

Fig. 2. Effect of ageing are not adequately described by ongoing hydration (HS Müller, TG10.1 meeting, Barcelona 2017)

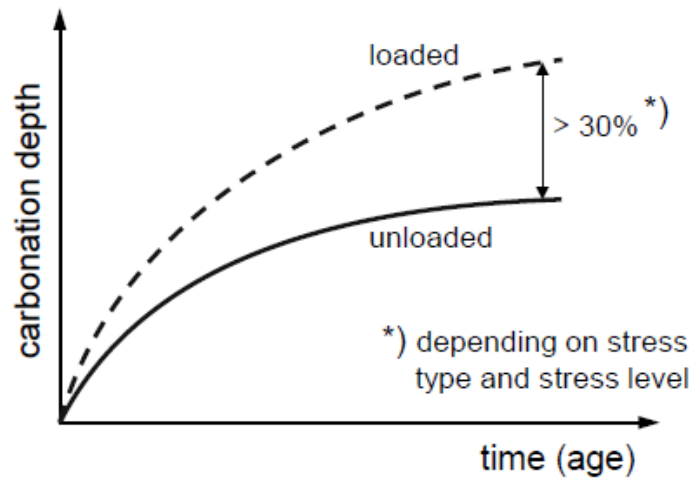

Fig. 3. Effects of structural loading stress on carbonation depth (HS Müller, TG10.1 meeting, Barcelona 2017)

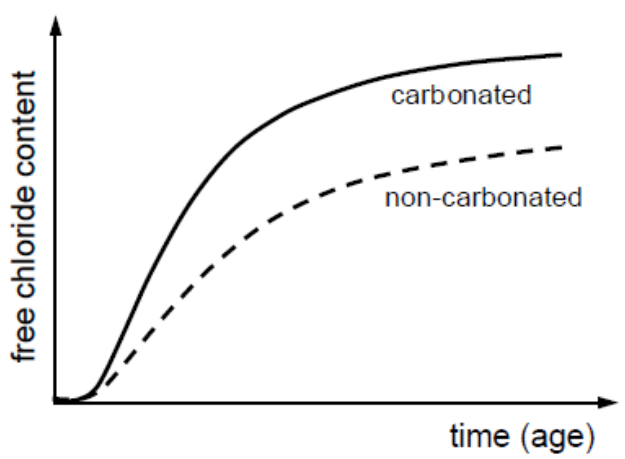

Fig. 4. Effect of carbonation on chloride binding capacity of concrete (HS Müller, TG10.1 meeting, Barcelona 2017)

Finally, measurement methods have to be defined in order to determine the properties of structural materials in existing structures subject to deterioration.

In all cases where material properties are measured, both the mean values and the coefficient of variation have 
to be determined to facilitate reliability based assessments of structural \& durability / other performance characteristics.

\section{Existing concrete structures}

Existing concrete structures are often appreciably different entities to the new concrete structures which contemporary design and construction practices create. The differences generally relating to the age / period when the structures were constructed, the implicit assumptions contained in the codes used for their design and in the supporting material / product standards of those earlier times.

Depending upon the period of their construction, existing structures may contain obsolete structural details which do not comply with contemporary practices; a situation which may produce sub-optimal behaviour in some regions of the structure for failure modes associated with shear, punching and torsion. Clearly the implications of such structural details need to be evaluated. However, this is not always an easy undertaking and work needs to be undertaken in MC2020 to provide assessment guidance that enables proper consideration of the actual structural detailing of existing concrete structures.

Existing structures are often composed of materials with different characteristics to those employed in concrete structures which are being built now. This applies to both the cementitious materials and the reinforcements used.

While the specified, typically 28 day, concrete strength was usually much lower than that which is employed today, the actual (contemporary) strength in an existing concrete structure can be significantly higher depending upon the extent to which subsequent in-service hydration of the coarse cement particles took place.

The nature, condition and behaviour of existing concrete structures can be investigated, allowing a prognosis to be made about their future condition and performance. However, investigations can be difficult to undertake and which leave significant uncertainties that have to be addressed in the structural assessment process.

Existing structures may have experienced damage or deterioration - it is important to establish what the influence will be upon the current and future characteristics of the concrete and steel. This may be an essential first step towards making structure management and intervention decisions for an existing structure.

Certain structural materials and components are not used anymore, such as plain or indented reinforcing steel. Consequently, most modern (contemporary) codes and recommendations are based on the assumption that standardised ribbed reinforcing steel bars are used as reinforcement and, accordingly, modern codes do not include provisions for use or evaluation of previous types of reinforcing materials. Thus, modern design rules can have limited applicability for use in the assessment of older existing structures and therefore need to be applied with great care.

Accordingly it is intended that MC2020 will pay particular attention to the issues specific to existing structures, such as the effect of material degradation and / or insufficient or deficient detailing of the provided material and / or of the member behaviour models. There is a need for improved models and the treatment of uncertainties in models / model parameters for existing structures and (phased) interventions.

Thus an important consideration is to include relevant structural models which apply not only to the design of new structures, but also to the determination of the load capacity / structural reliability, serviceability, remaining service life etc of existing structures taking account of:

- Load-carrying behaviours not considered in design / addressed in the formulation of contemporary design, equations, such as compressive membrane action.

- Structures which utilise inappropriate / non-compliant structural details / detailing including:

$\circ$ Where the shear reinforcement is less than the prescribed minimum percentage

- Smooth reinforcing bars (without surface ribs)

- Non-compliant anchorage details / lap lengths, etc

- Load carrying behaviours in deteriorated members and structures, which are different to those of members that have not experienced deterioration or damage. The magnitude and nature of the differences typically increases for greater degrees of deterioration / damage. The forms of deterioration include:

- Reinforcement corrosion / prestressing and the associated adverse effects upon:

$>$ Reinforcement - concrete interface bond

$>$ Ductility of the steel

$>$ The properties / performance of concrete members which have cracked

- Degradation of the concrete by ASR, various types of sulfate attack, freeze-thaw, acid attack, etc

In regard to load-carrying behaviours not considered in design which act to enhance structural capacity, in addition to compressive membrane action mentioned above, there are also factors such as the increase in concrete strength above the specified characteristic value, along with the change in concrete properties during the life of a concrete structure, which are not usually taken into account. In addition, advanced methods of structural analysis (eg. calibrated non-linear finite element analyses) are able to provide better / more accurate estimates of the load capacity of individual members, as well as of assemblages of elements mobilising system / wholebuilding behaviours.

In regard to load-carrying behaviours in deteriorated members and structures, the issue is mainly related to bond deterioration in reinforced concrete. A reduced flexural bond strength permits reinforcement slip and, more importantly, the development of an arching effect in flexural members.

Corrosion of reinforcement adversely affects the behaviour of concrete beams in various ways, typically increasing both the beam deflection and the width of cracks at service load levels, and potentially greatly reducing the strength at ultimate load. Corrosion of reinforcement also modifies the type of failure experienced; with the corrosion of stirrup (shear) reinforcement being observed to often have the most significant influence and to potentially result in the shear failure of affected beams, whereas undamaged control 
beams failed in bending. Conversely it is also possible for short beams, which would normally fail in shear, to collapse as a result of the rupture of the main longitudinal reinforcement. Such a failure could occur if corrosion had produced severe pitting which greatly reduced the crosssectional area of the main reinforcement at some locations. In these circumstances corrosion would have greatly diminished the strength of the tie stabilising the in-beam arching behaviour mentioned above.

When fatigue effects are combined with corrosion surface crack widths in concrete members can increase dramatically, being up to twice those in members where the reinforcement has not experienced corrosion - for the same number of fatigue cycles. This typically results in the complete debonding of the reinforcement. In the situation where the reinforcement is not corroded, a surface crack in a concrete member would be expected to increase in width by some $10-15 \%$ after several million load cycles. Additionally, fretting fatigue which occurs in the vicinity of cracks, perhaps generated by thermal and shrinkage effects, accelerates the process of bar diameter reduction, so creating regions of weakness distributed along the length of the reinforcing bars.

\section{Forensic engineering aspects}

\subsection{Components of 'Forensic engineering'}

What is 'Forensic engineering' and what do practitioners mean by the use of the term? It is perceived that different practitioners apply the term in significantly different ways and therefore assign appreciably different meanings to it.

The following definition of forensic engineering is taken from $f i b$ Bulletin 62 [13]:

Forensic engineering: The application of engineering knowledge to the investigation and assessment of the nature, condition and performance of an engineered system. Commonly this is associated with the use of scientific methods and engineering principles to the study of the processes of deterioration or abnormal changes within or failure of structures, buildings or other constructed facilities or elements thereof; together with their causes, symptoms and remediation and the associated methods of investigation and assessment.

Other terms are used for these and similar activities. CIB - The International Council for Research and Innovation in Building and Construction - uses the term 'Building pathology' and defines this to be 'the systematic treatment of building defects, their causes, their consequences and their remedies'. CIB's work in this area is undertaken within Commission CIB W086: Building Pathology, which is basically concerned with learning from past and current building pathologies and encouraging the systematic application of that knowledge to the design, construction and management of buildings.

CIB Publication 393 [14] indicates that building pathology provides a systematic scientific approach to discovering what has gone wrong with a failed building and that a building pathologist is primarily concerned only with what has happened and how it came to happen. CIB W086 states that a building pathologist's main focus is to ascertain the facts of the situation, rather than to attribute blame or liability.

In a structural engineering context, forensic engineering typically involves the investigation of various types of failure of constructed facilities in order to determine the potential cause(s) of the failure, but also to identify the parties which bear responsibility for the event. This highlights an interesting difference in the foci of building pathology and forensic engineering activities.

While collapses and fires are dramatic forms of failure, forensic engineering and building pathology studies also examine failures / non-compliances in respect of serviceability, durability or other forms of performance requirement. Key components in these activities are commonly investigation, sampling and testing, but these may also include monitoring and various types of advanced analytical / simulation studies to aid the interpretation of findings and development of prognoses about past performance and / or future behaviours. These processes / procedures allow the potential influence of various technical and organisation factors to be systematically and rigorously examined.

There are many examples of forensic engineering / building pathology studies which identified necessary improvements in design and construction practices, resulting in a legacy of such improvements within the wider construction industry. Ultimately such studies have improved the overall quality and safety of the constructed assets forming the built environment; a situation which the public is commonly unaware of and generally takes for granted. These studies have provided an extremely valuable source of carefully derived information which provides an important educational resource which, amongst other matters, has contributed to the profession's understanding of structural and material behaviours, the evolution of design theory and analytical processes and contemporary standards of professional practice.

Amongst others Carper [15] has reviewed the contribution made by failure investigations / forensic engineering studies to knowledge. He also outlines some of the activities of the ASCE Technical Council on Forensic Engineering, which was established in 1985 [16].

Forensic engineering / building pathology studies are also employed to provide insight into the potential consequences of active deterioration and damage processes, as well as allowing the study of ways in which remedial / preventive works can be employed to improve the performance or extend the useful life of existing structures / constructed assets. Such types of studies can have significant sustainability benefits if they are able to prolong the effective use of existing constructed assets.

It is also necessary to link the technical aspects of forensic engineering / building pathology activities with the associated professional, ethical conduct and procedural aspects. These include matters such as how investigations are conducted, how data and evidence are gathered and analysed, what quality control measures are employed in the work, as well as how test results and other data are to be evaluated and interpreted to arrive at the final assessment. Matters such as the chain of custody of evidence can be critical in situations where criminal prosecutions are anticipated. 
There are also growing expectations in some regions of the world that those undertaking expert work / forensic investigations (or similar) should be accredited by an appropriate professional or regulatory body. Experts are also commonly expected to undertake regular continuing professional development activities to enhance the standard of their professional practice and in support of their periodic revalidation.

\subsection{Some MC2020 developments}

It is proposed that MC2020 utilise the advances which have occurred in numerical analysis, monitoring and in sensor techniques to improve the through-life care and management of existing concrete structures.

While numerous aspirational goals have been identified for MC2020, those particularly relevant to forensic investigations of existing concrete structures include structural (strength) assessment, as well as to matters relating to durability and service life performance:

- Models for concrete deterioration processes not adequately addressed in fib MC2010 (eg ASR, various types of sulfate attack, freeze-thaw, acid attack, etc),

- Material deterioration models addressing propagation stage deterioration of both reinforcement and concrete.

- The influence of cracking, in association with consideration of a wider range of aggressive service environments and situations, upon the potential for significant localised corrosion of reinforcing bars intersecting cracks.

- Structural (mechanical) models for deterioration / damage effects

- Structural (mechanical) models for structures with inappropriate / non-compliant structural details / detailing including:

- Where the shear reinforcement is less than the prescribed minimum percentage

- Smooth reinforcing bars (without surface ribs)

○ Non-compliant anchorage details / lap lengths, etc

- Material deterioration models and structural (mechanical) models for 'repaired' structures / intervention behaviour

- Consideration of the use and value of monitoring data / the level of knowledge available for decision making in the through-life management and care of concrete structures.

It is expected that non-linear FEM analysis will be increasingly used in the future for both:

- new structures characterised by high structural complexity and/or special details or by use of special materials, and for

- existing structures in both their original state or after interventions have been performed.

\subsubsection{Levels of Approximation (LoA) approach}

Where practicable, it is proposed that MC2020 will offer models providing different levels of sophistication and thereby different levels of approximation (LoA) / accuracy for different magnitudes of analysis and verification effort - as portrayed pictorially in Figure 5.

The lowest LoA Level (I) can be used when high accuracy is not required, such as for preliminary design or structural assessment activities. The highest LoA Level (IV) would be used when the greatest accuracy is required, such as when making an assessment of the global behaviour of a critical structure. Clearly undertaking a Level I analysis would involve far less effort and cost than performing Level IV analysis, which takes into account of a wider range of mechanisms contributing to the transfer of the applied loads or other actions to the supports.

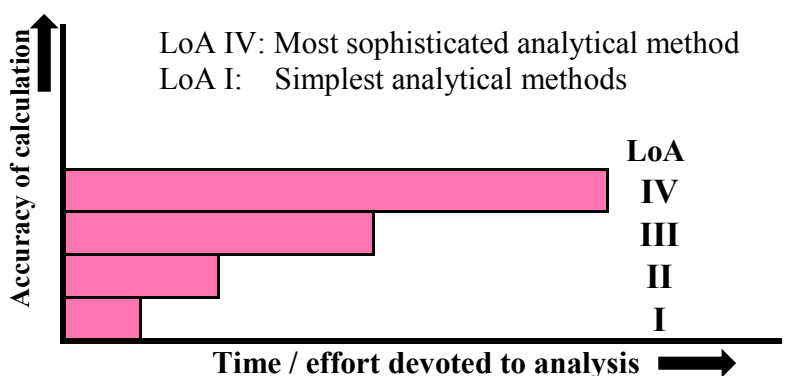

Illustration of potential Levels of Approximation (LoA):

IV System / global assessment of critical structures / design of special cases / situations

III In-depth elemental evaluation of existing structures design of special cases / situations

II Typical elemental design / assessment

I Preliminary design and assessment evaluation, nongoverning limit state design / assessment outcome

Fig. 5. MC2020 Level of Approximation approach.

The figure portrays 4 potential levels of approximation sophistication in the forms of analysis that may be employed.

The results from a Level I analysis need to be appreciably more conservative than the results of higher LoA levels. The intention is that where possible the lower LoA levels represent simplifications of the highest LoA level and corresponding produce appropriately more conservative outcomes.

The LoA approach is a particularly useful approach for activities undertaken for the verification of the performance of existing structures, where additional analytical effort may be able to demonstrate that a satisfactory level structural reliability or other form of performance is being achieved; thereby avoiding the often considerable expense and disruption associated with the need to undertake a physical intervention to improve structural performance.

The most appropriate level of approximation for the case being considered will depend not only on the stage of verification process, e.g. initial or in-depth assessment, but also on the complexity and importance of the element and the structure / under consideration. It is proposed that the LoA approach be employed for the assessment of structural and other forms of performance, such as durability / service life evaluation.

Walraven [17] mentions the use of the LoA approach in the context of determining the real bearing capacity / strength of existing structures. The first example is 
concerned with estimating the actual punching shear resistance of thin bridge deck slabs supported on top of prestressed deck beams (spanning longitudinally). The thin deck slab was subjected to increased traffic loading but had an enhanced load bearing capacity due to its ability to mobilise compressive membrane action. Consideration of behaviours not taken into account in the design code rules allowed the development of a structural model which was able to show that the thin bridge deck slabs had adequate punching shear resistance.

Walraven's [17] second example examines the application of non-linear finite element modelling (say a LoA Level IV approach) to the verification of the safety of the immersed tube Mass Tunnel in the Netherlands when it was discovered that the cross-section of the bending reinforcement in the bottom slab had been substantially reduced by corrosion. It was also indicated that a much simpler analysis (perhaps a LoA Level I approach) was also able to demonstrate that tunnel walls and slabs were effectively precompressed axially by the external ground water pressure and remained in compression, such that it was not necessary to close the tunnel as a result of the reinforcement corrosion which had been discovered in the tunnel base slab.

\subsubsection{Use of testing and monitoring procedures}

Testing and monitoring provides reliable data on the real conditions and behaviour of structures, and may enable reduction of uncertainties in the assessment and prediction of the performance of the structures. In-situ load testing and proof loading may be a useful tool for the definition of structural behaviour and for the updating of the numerical models describing the structure; specific provisions for the use of such special types of test on the structure will be given in the MC2020.

Monitoring is becoming a fundamental tool to understand the evolution of structural behaviour with time and to allow a predictive, instead of reactive, policy to be used to control when interventions are undertaken and their form (eg. maintenance activities, targeted preventive works or remedial / reconstruction works).

The developing availability of low-cost micro-sensors (MEMS) will allow their extensive use in the measurement of local behaviours (eg. crack opening evolution, stress levels) and overall behaviour (eg. displacements, rotations, accelerations). It is envisaged that MC2020 will give suggestions for the treatment of large data sets (Big Data) produced by monitoring. These processes are expected to involve the use of specific algorithms and by the development of self-diagnosis procedures.

\section{Case studies of existing concrete structures}

The following present some (simplified) case studies / application examples for existing concrete structures which have experienced damage / deterioration / other inadequacies and associated intervention works. These examples illustrate the use of a range of procedures that may be applied in forensic engineering investigations and structural assessments.

\subsection{Highway bridge A - Monitoring case study}

This case study presents a real-time monitoring system based on MEMS technology clinometers installed on a concrete highway bridge in the south of Italy. The main goal was to provide the infrastructure owner with useful information regarding bridge structural behaviour, in order to predict possible failures and damage / deterioration processes, as well as to characterise bridge responses under different load conditions.

The need for monitoring arose following the brittle failure of one span on one carriage way during its demolition. The failure occurred because of a discrepancy between the as-built drawings and the actual structural details, in particular with reference to the layout / location of the pre-stressing tendons.

The considered bridge consists of three central steel spans connected to the north and south abutments by seven and nine pre-stressed concrete girders respectively. The east span was chosen for instrumentation due to its accessibility. Figure 6 shows the plan view of the entire bridge. The pre-stressed concrete spans, similar to each other, are about $40 \mathrm{~m}$ long and consist of a concrete deck supported by four pre-stressed concrete girders, connected by five lateral beams. Five clinometers were installed on each span, fixed to the core of the outermost beam.

In order to capture the bridge deformation under traffic excitations, a total of 80 integrated MEMS were instrumented on the bridge, 35 in the north and 40 in the south spans, respectively. Sensors are positioned at the bottom of every girder and are connected to a control unit which sends data directly to the 'Cloud' in real-time.

Figure 7 illustrates the instrumentation setup locations.

\subsubsection{SHM methodology}

Each sensor acquires data with a predetermined sampling frequency, identified on the basis of the monitored parameters of interest, in this case inclinations. In particular, the bridge response is sampled sequentially starting from the control unit at $100 \mathrm{~Hz}$ for a predetermined time interval.

In order to compare the deformation values obtained through the installed monitoring system and the expected bridge structural behaviour, a FE model was developed using the SAP2000 software. Deck members and bridge system components were represented by beam elements to obtain the lowering values of the external beams, on which sensors have been installed. To better understand the structure, a thorough document review was carried out in addition to a site visit in order to identify all pieces of information needed to construct the FE model, such as geometry, cross sections, material properties, boundary conditions, and any changes in the structure over its life. 


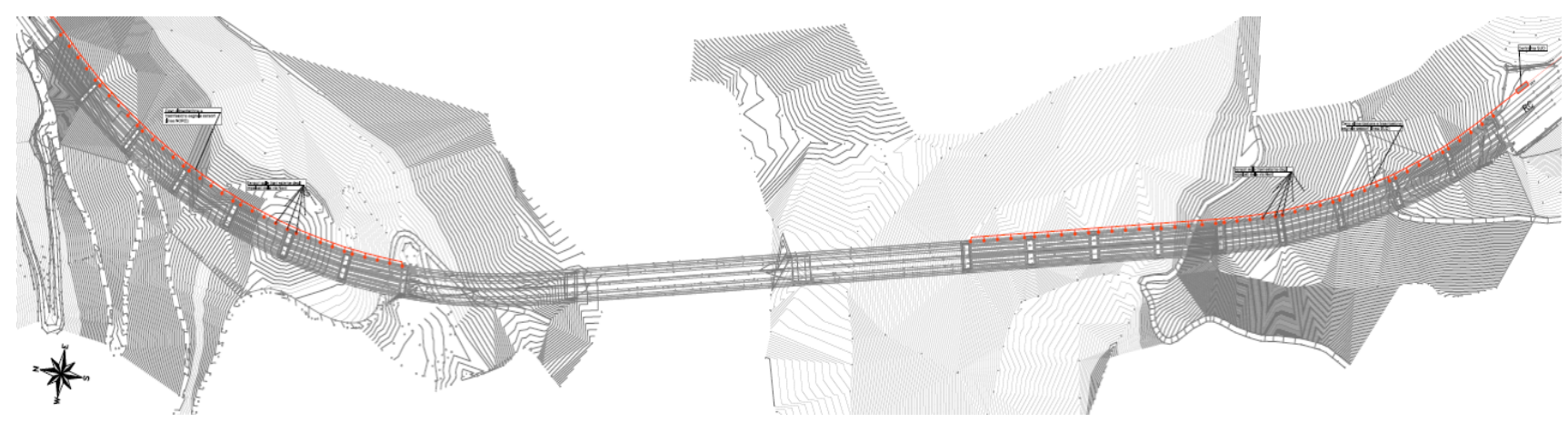

Fig 6. Plan view of highway bridge A
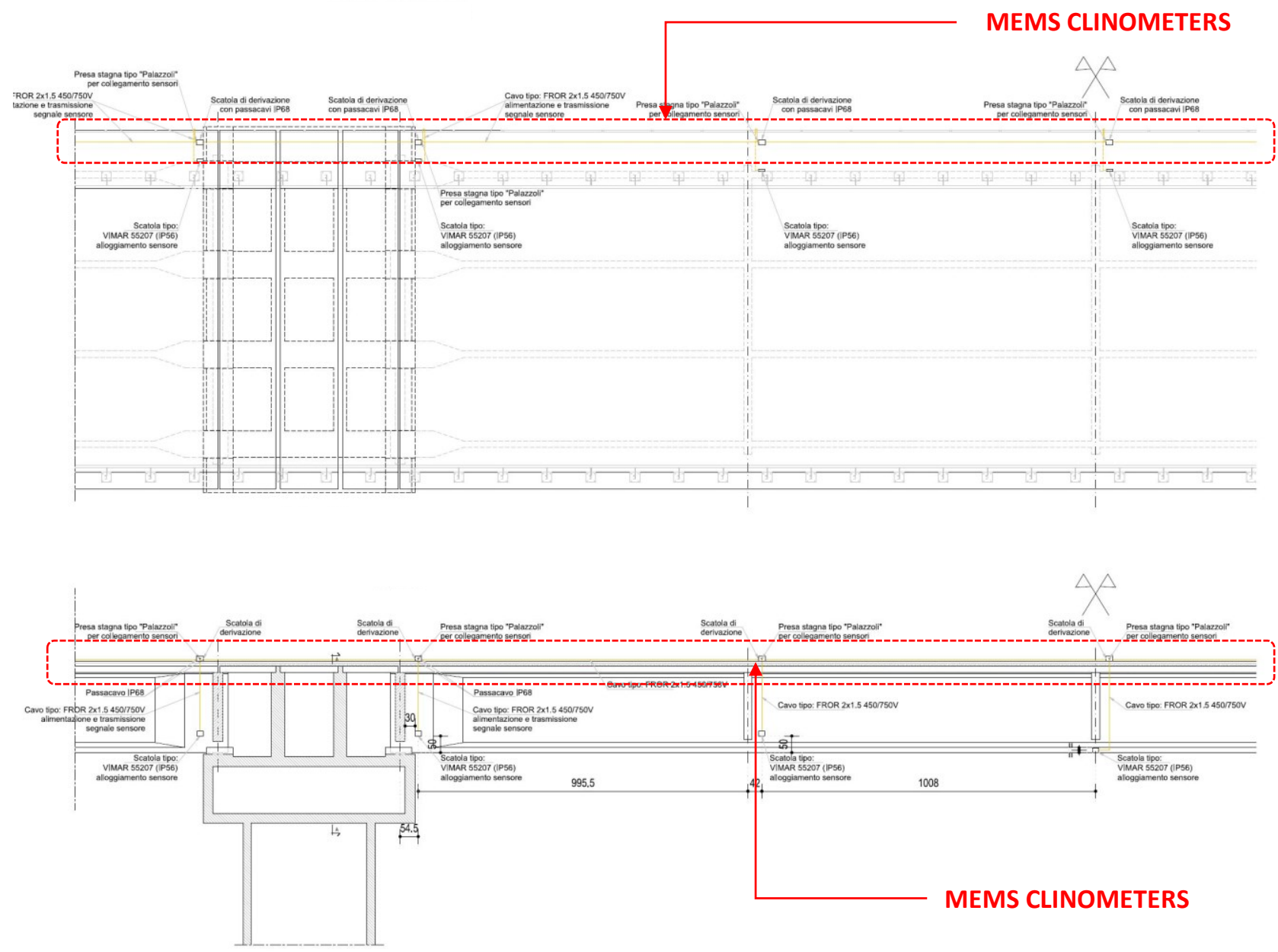

Fig 7. Positioning of Clinometers along the deck of highway bridge A

Using results from the FE model, threshold values have been set, based upon information collected though the monitoring system at regular intervals. At every sensor reading interval, thresholds are applied to the collected data. Two different threshold types are generated, depending on the structure security levels:

1. Attention alert: is the first threshold level, at which point the bridge has no critical behaviours. Starting from this point, the structure requires attention.

2. Critical / Trouble alert: when the structure has reached a critical level which could lead to a partial or total loss of service (permanent damage). At this point, the structure demands immediate attention.

\subsubsection{SHM results}

Figure 8 presents a time history of the readings obtained from one sensor positioned on the centreline of the second span of the bridge. The graph shows the rotations measured over time by the installed clinometer, compared with the rotations corresponding to the calculated threshold values for the different alarm levels. 


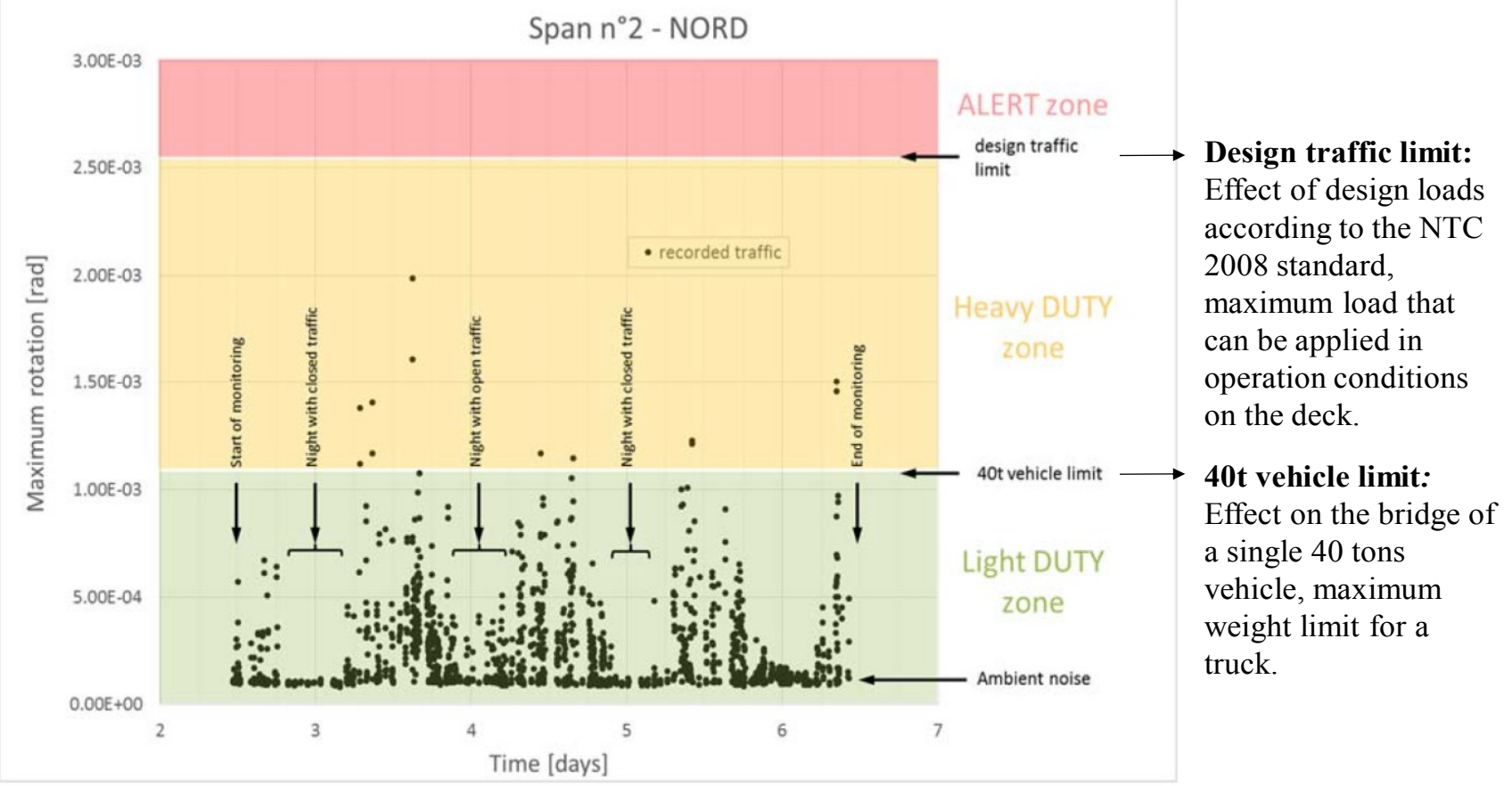

Fig 8. Safety assessment example for highway bridge A

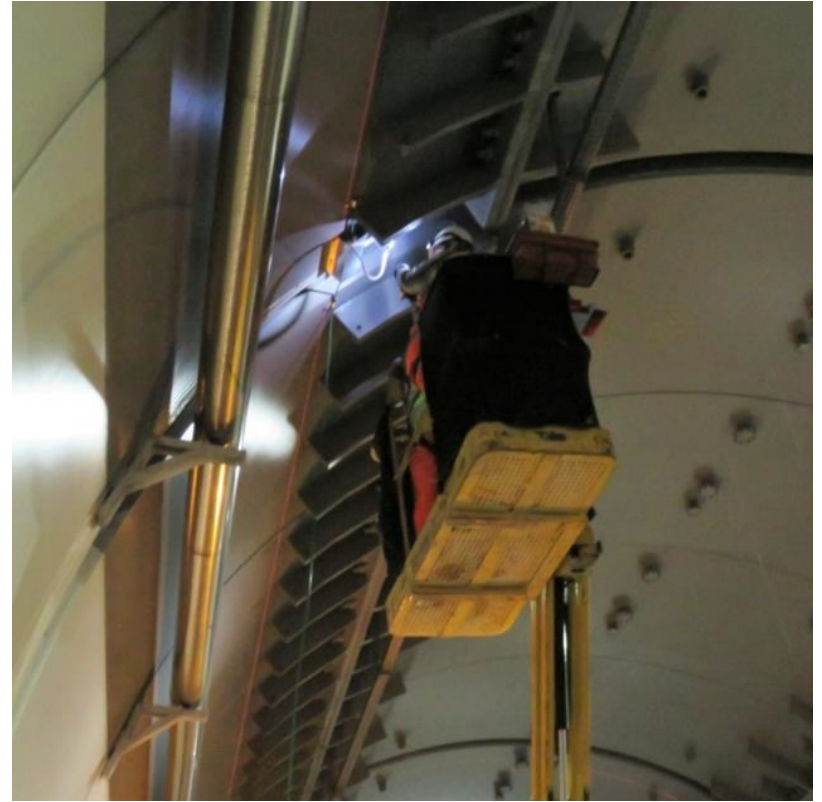

Fig 9. MEMS Sensors installation in the monitored tunnel

\subsection{Tunnel monitoring case study}

This section illustrates the application of MEMS clinometers as part of an innovative and advanced structural health monitoring (SHM) system for tunnel monitoring. Owing to their unique design and construction, tunnels call for rigorous SHM programmes during both construction and operation phases. Indeed, their continuous monitoring can serve to mitigate potential hazards, ensure better performance and facilitate in-depth understanding of the overall structural behaviour. In particular, data from a real-time monitoring system installed in a tunnel located in central Italy are presented Figure 9 illustrates the instrumentation installed.

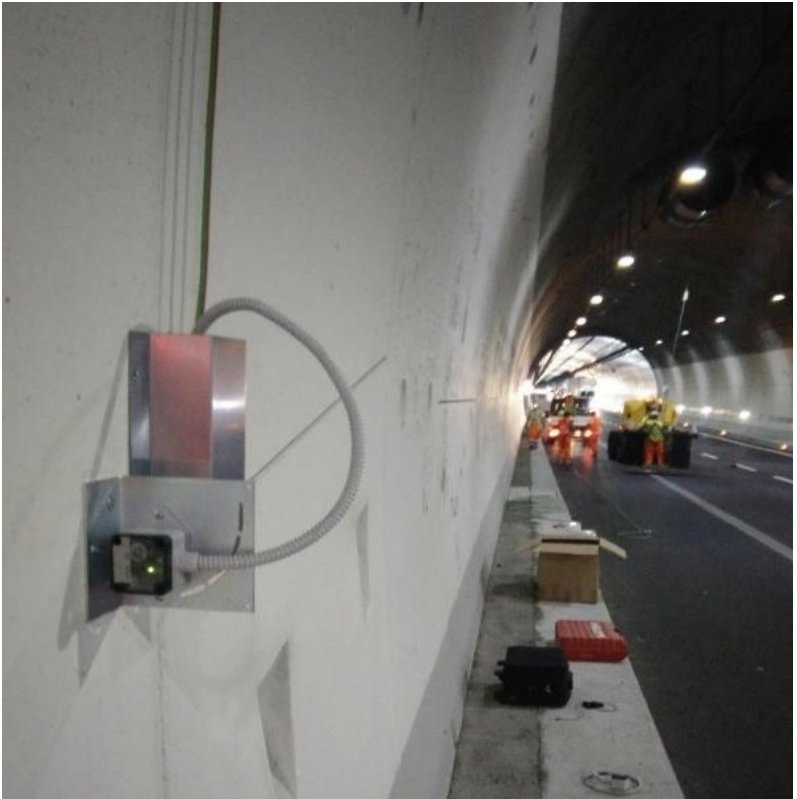

The infrastructure being monitored is a double-arch tunnel, one for each direction of travel, about $2 \mathrm{~km}$ long, housing a 3-lane roadway. The tunnel was constructed using a TBM machine, which installed precast concrete lining segments whilst tunnel excavation was undertaken.

Monitoring of the tunnel was necessary given the presence of a landslip system which crosses the line of the tunnel, and is the source of the ongoing lateral soil displacements. While the earthflow displacements are slow, they are ongoing continuously creating lateral soil movements in the order of one to several $\mathrm{mm}$ per year. The landslip-tunnel interaction is rather complex to analyse, since it may be influenced by not only the geological condition, the tunnel structure design and the 
construction environment, but also by the lack of information regarding the real infrastructure and soil behaviours during the working life of the tunnel.

\subsubsection{SHM methodology}

The alarm indices are generally stipulated based on the total variations and the variation velocities of the monitored parameters, with the proviso that the warning value of the total variation should not be larger than the design value.

Short and long-term tunnel behaviours have been reproduced through finite element modelling in order to represent the structure's pre-existing stress state at the time of installation of the monitoring system and its theoretical evolution expected over a 60 year period from tunnel excavation. The FE model was representative of the theoretical tunnel stress state at the beginning and at the end of monitoring. Threshold values were set, based on the information collected at regular intervals by the monitoring system.

The monitoring system was designed to systematically acquire information on the tunnel behaviour by reading the deformation response of the infrastructure while it is in service. For this purpose, tunnel interior walls have been instrumented with a total number of 762 MEMS clinometers. The monitoring system provides arrays of sensors around the tunnel circumference, installed at several transverse sections and integrated with longitudinal connections (Figure 10), with there being sufficient redundancy in the sections where the impact of the landslip on the tunnel is more significant.

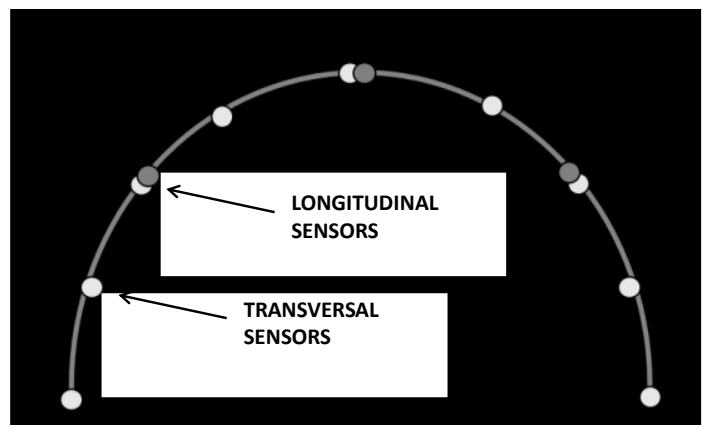

Fig 10. Sensors positioning along the tunnel transversal section

The sampling frequency has been set on the basis of the chosen parameter of interest. The overall monitoring system has been set up to record real-time displacements of the infrastructure, so a number of accessory parameters such as temperature, humidity, readings and standard deviation values etc. have been collected. The acquired data were stored on a 'Cloud platform' where they could be processed and analysed to obtain data useful for structural analysis.

A specific data processing algorithm was developed in order to analyse clinometer readings and to provide efficient real time tunnel monitoring. Indeed, raw data from the clinometers was affected by "noise" generated by several causes. For this reason, a specific data processing framework was proposed in order to eliminate data errors arising from the environment, from the inherent sensor noise etc...

After the preliminary data processing, the parameters of interest for the structural analysis are calculated in terms of both displacements and rotations for the monitored tunnel points. The displacement shapes can thus be derived for each instrumented tunnel transversal section at a given moment in time, creating a powerful means of monitoring infrastructure deformation in real-time.

Figure 11 shows the development of the tunnel crosssectional displacements with time (for a generic transverse section) for the initial measurement time period. The figure presents amplified movements (magnification factor of 100) to show the rotational-translation effect on the tunnel cross-sectional profile caused by the landslip movement.

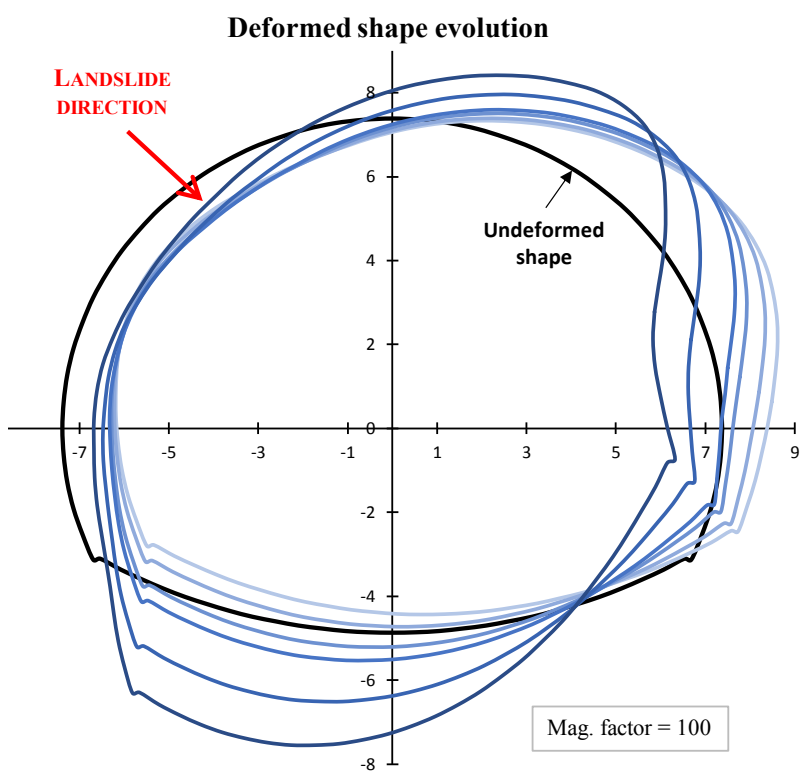

Fig 11. Results for a selected tunnel transversal section

\subsection{Monitoring of the external steel tendons of highway bridge $B$}

External pre-stressing is increasingly being used, especially in motorway bridge structures, due to the substantial savings which can be made in terms of construction time. In such systems, internal and external steel tendons are one of the main load-carrying components. This means that the deterioration or breakage of these elements can be catastrophic for the entire structure. For this reason, real time monitoring of pre-stressing tendons should provide useful information from the inside of the bridge subject to service loads, detecting possible fatigue and damage / deterioration processes.

This section describes the application of MEMS accelerometers in a high performance and cost-effective SHM system for bridge structures.

The monitored structure is a highway concrete bridge located in the centre of Italy. It has spans of $120 \mathrm{~m}$ and a total length of about $580 \mathrm{~m}$, with a cross-section height varying from $6.0 \mathrm{~m}$ (at the bearings) to $3.0 \mathrm{~m}$ (on the centreline of the span). 
The monitoring was instigated to check the behaviour of external tendons with time after a failure of one tendon composed of 27 strands, by effect of an incorrect grout composition. Figure 12 shows the plan view of the monitored concrete highway bridge $\mathrm{B}$.

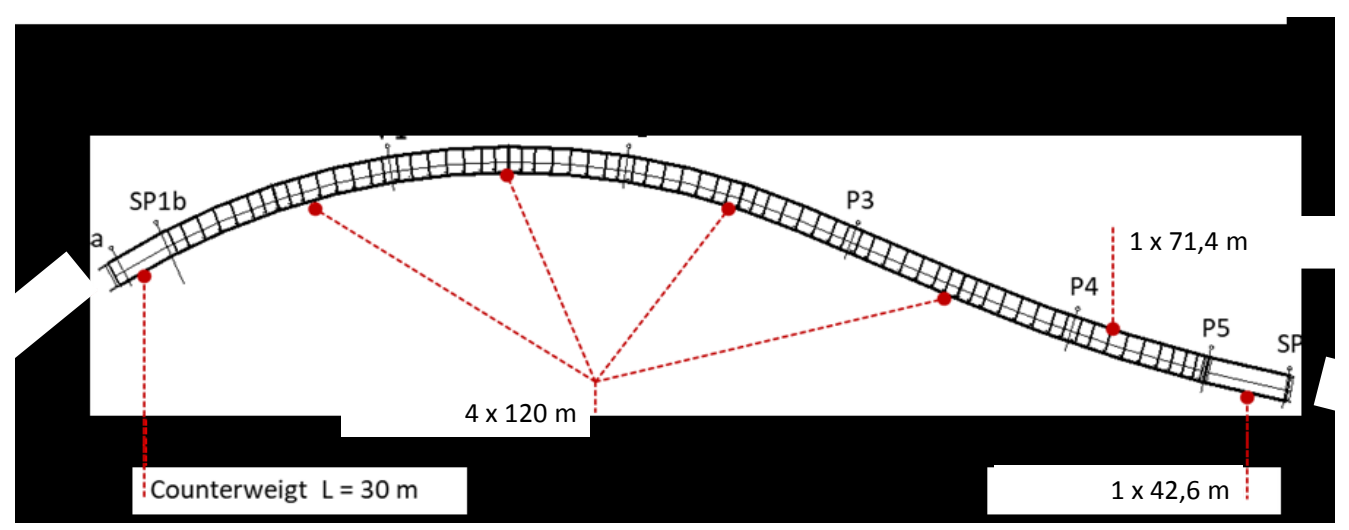

Fig 12. Plan view of highway bridge $B$

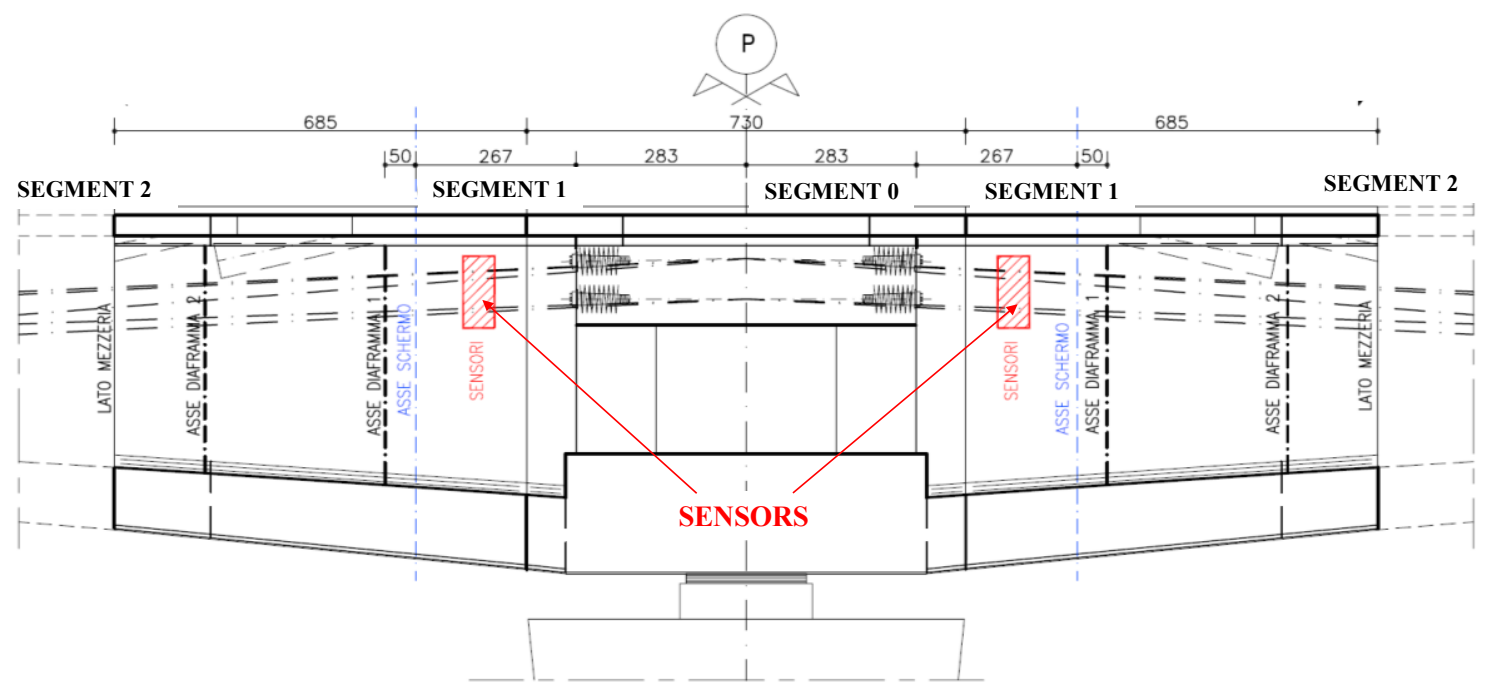

Fig 13. Clinometers positioning - transverse section of highway bridge $B$

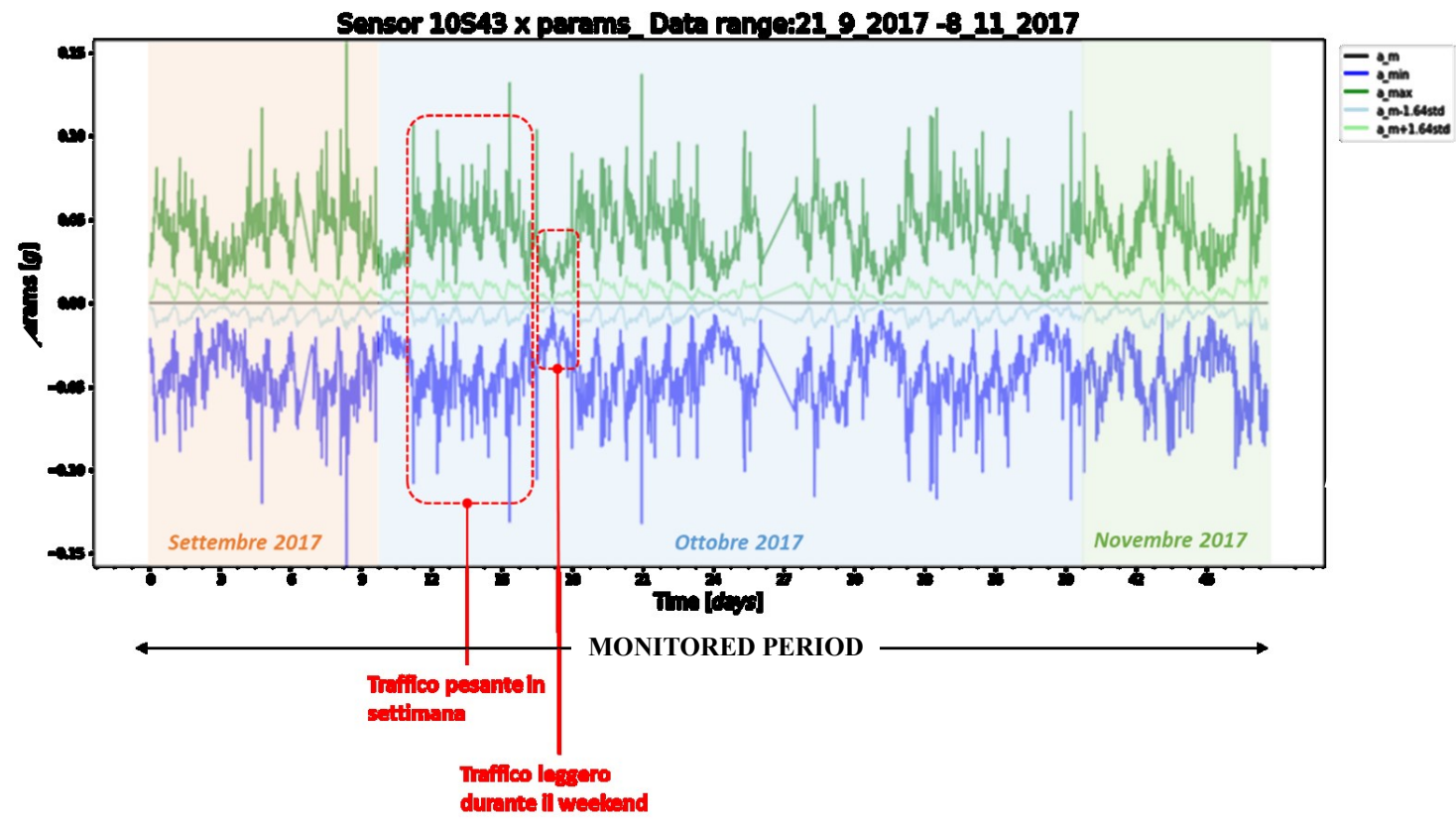

Fig 14. Data from one accelerometer on highway bridge B 


\subsubsection{SHM methodology}

The described concrete bridge was instrumented with a continuous monitoring system for the real-time detection of the condition of the strands during the service life of the structure. Indeed, external bridge tendons have been instrumented with a total of 88 tri-axial accelerometers, 2 for each monitored tendon.

The service life of tendons in pre-stressed structures depends on the behaviour of the steel strands that form them. Application of MEMS accelerometers can thus provide structure owners with a measure of the fundamental properties necessary to predict the long-term performance of the bridge.

In particular, changes in the dynamic characteristics of the monitored elements have been analysed by detecting the shift in tendons' natural frequencies. A specific data processing algorithm was developed in order to analyse the collected sensors' data and provide efficient real-time tendon monitoring.

Each tri-axial MEMS accelerometer provides data in the 3 orthogonal directions $(\mathrm{x}, \mathrm{y}, \mathrm{z})$; in this way it is possible to capture the bridge vibration and deformation under traffic excitations and to obtain bridge modal properties. In fact, bridge vibration responses are measured under different traffic conditions as shown in Figure 14. The trends observed during the monitored period allowed the definition of a benchmark of measurements corresponding to the standard behaviour of pre-stressing tendons subject to traffic conditions or nonexceptional external loads.

Several sets of data under regular traffic excitation have been collected and, consequently, threshold levels (attention / alarm) have been defined for the monitoring system.

The monitoring system is also able to control the bridge response after accidental actions, such as earthquakes with their epicentre located in adjacent regions.

\section{Concluding comments}

The new and extended models to be incorporated in MC2020, in association with the other aspects of the updated guidance, should provide improved technical capabilities for undertaking forensic engineering studies. For example, the benefits of the MC2020 improvements are expected to include:

- More accurate estimates of the actual strength / bearing capacity of structures, especially as they age / deteriorate.

- Better ways of estimating the change in structural reliability as structures age / deteriorate.

- Verification of existing structures by testing, such as the use of proof loading procedures.

- Improved interpretation of data obtained from throughlife inspections, testing and monitoring, along with the prognoses made concerning future behaviour and deterioration of the structure.

- More effective ways of estimating the behaviour of 'repaired' structures.
The improved technical capabilities should allow forensic engineers gain a better understanding of the physical behaviour of existing concrete structures, enabling them to make better judgements about how the structures have behaved in-service or may potentially behave in the future (ie. prognoses about future behaviour), what level of structural reliability they might be expected to have and what measures / interventions might be appropriate to extend their useful life.

The wider legacy of improved technical capabilities for undertaking forensic engineering studies should be better understanding of the behaviour of structures and the processes / procedures involved in their creation and through-life care, along with improved design, assessment, construction and intervention practices.

\section{References}

1. United Nations, Transforming our world: The 2030 Agenda for Sustainable Development, Resolution 70/1 (25 September 2015).

2. fib MC2010, fib Model code for concrete structures 2010, Fédération Internationale du Béton (fib), Lausanne, Switzerland, published by Wilhelm Ernst \& Sohn, Berlin (2013)

3. ISO 16311-1. Maintenance and repair of concrete structures - Part 1: General principles. Geneva, International Organisation for Standardisation (2011).

4. ISO 16311-2. Maintenance and repair of concrete structures - Part 2: Assessment of existing concrete structures. Geneva, International Organisation for Standardisation (2011).

5. ISO 16311-3. Maintenance and repair of concrete structures - Part 3: Design of repairs and prevention. Geneva, International Organisation for Standardisation (2011).

6. ISO 16311-4. Maintenance and repair of concrete structures - Part 4: Execution of repairs and prevention. Geneva, International Organisation for Standardisation (2011).

7. BSI Eurocode: Basis of structural design. BS EN 1990. London, BSI (2002).

8. BSI Eurocode 2. Design of concrete structures. General rules and rules for buildings (including National Annex). BS EN 1992-1-1. London, BSI (2004).

9. BSI Eurocode 2. Design of concrete structures. General rules. Structural fire design (including National Annex). BS EN 1992-1-2. London, BSI (2004).

10. ISO 2394. General principles on reliability for structures. Geneva, International Standards Organisation (2015).

11. ISO 16204. Durability - Service life design of concrete structures. Geneva, International Organisation for Standardisation (2012).

12. HS Müller, Concrete Chapter in MC 2020 Advanced approaches for code-type models, contribution to fib TG10.1: MC2020 meeting, Barcelona (11-12 December 2017). 
13. fib Bulletin 62, Structural concrete: Textbook on behaviour, design and performance, 2nd Edition, Volume 5 - Chapter 9: Through-life care and management of concrete structures - Assessment, protection, repair and strengthening, Fédération Internationale du Béton ( $f i b$ ), Lausanne, Switzerland (2012).

14. CIB Publication 393, A state-of-the-art report on building pathology, prepared by CIB - W086: Building Pathology. CIB General Secretariat, Rotterdam, the Netherlands (2013).
15. KL Carper, Quality and safety: The ultimate legacy of forensic engineering, Proceedings Forensic engineering - Neale (ed.), Institution of Civil Engineers, London, p13-25 (2005).

16. www.asce.org/forensic-engineering/forensicengineering-division

17. J Walraven, Forensic engineering: Need for a new professional profile, Proceedings fib Symposium, Cape Town, South Africa, 21-23 November 2016, p73-82. 